\title{
EL RECORDATORIO A LA DETERMINACIÓN DEL CONTENIDO ESENCIAL DE LOS DERECHOS FUNDAMENTALES, ATENDIENDO EL ESCENARIO DE LA PANDEMIA POR EL COVID-19 EN EL ESTADO COLOMBIANO
}

\author{
Carolina Blanco Alvarado \\ Universidad Católica de Colombia
}

\section{Resumen}

Este manuscrito pretende una aproximación global al contenido esencial de los derechos fundamentales, como prestaciones positivas y negativas que debe garantizar el Estado. Si bien la doctrina ha gestionado teorías que explican a dicha institución como límite a la actividad legislativa, no existe explicación unívoca de lo que significa el contenido esencial de los derechos fundamentales: se considera que es la misma dignidad humana. Los objetivos del presente manuscrito se circunscriben a identificar la dogmática jurídica en el marco del contenido esencial de los derechos fundamentales, a establecer críticas a la referenciada dogmática jurídica y a determinar una aproximación al contenido esencial de los derechos fundamentales. La metodología de investigación empleada en el manuscrito es de carácter cualitativo, en razón a que el problema de investigación planteado supuso analizar descriptivamente la naturaleza jurídica del contenido esencial de los derechos fundamentales. Lo anterior, desde el método de investigación descriptivo-documental, ya que el artículo se fundamentó en la doctrina existente sobre el tema en particular.

Palabras clave: contenido esencial, derechos fundamentales, dignidad humana.

El autor: doctora en Derecho, docente de la Universidad Católica de Colombia. Correo electrónico: rcblanco@ucatolica.edu.co

Recibido: 23 de julio de 2020; evaluado: 20 de septiembre de 2020; aceptado: 8 de octubre de 2020. 


\title{
A REMINDER OF THE DETERMINATION OF THE CORE CONTENT OF FUNDAMENTAL RIGHTS, CONSIDERING THE SITUATION OF THE COVID-19 PANDEMIC IN THE STATE OF COLOMBIA
}

\author{
Carolina Blanco Alvarado \\ Catholic University of Colombia
}

\begin{abstract}
This article seeks to undertake a global approach to the core content of fundamental rights, as positive and negative benefits to be guaranteed by the State. Although the doctrine has theories that explain this institution as a limit to legislative activity, there is no univocal explanation of what the core content of fundamental rights means: it is considered to be human dignity itself. The objectives of this article are limited to identifying legal dogma within the framework of the core content of fundamental rights, to provide a critique of the aforementioned dogma, and to determine an approach to the core content of fundamental rights. The research methodology used in the manuscript is of a qualitative nature, as the research problem posed involved a descriptive analysis of the legal nature of the essential content of fundamental rights. This was done using the descriptive-documentary research method, since the article was based on the existing doctrine on the subject in question.
\end{abstract}

Keywords: core content, fundamental rights, human dignity

Author: doctor in Law, professor at the Catholic University of Colombia. Email: rcblanco@ucatolica. edu.co

Received: July 23, 2020; evaluated: September 20, 2020; accepted: October 8, 2020. 


\title{
A RECORDAÇÃO DA DETERMINAÇÃO DO CONTEÚDO ESSENCIAL DOS DIREITOS FUNDAMENTAIS NO CENÁRIO DA PANDEMIA PELA COVID-19, NO ESTADO COLOMBIANO
}

\author{
Carolina Blanco Alvarado \\ Universidad Católica de Colombia
}

\begin{abstract}
Resumo
Este manuscrito busca uma abordagem global do conteúdo essencial dos direitos fundamentais como benefícios positivos e negativos que o Estado deve garantir. Embora a Doutrina tenha gerido teorias que explicam esta instituição como um limite à atividade legislativa, não existe uma explicação unívoca do que significa o conteúdo essencial dos direitos fundamentais. A própria dignidade humana é considerada o conteúdo essencial dos direitos fundamentais. Os objetivos deste manuscrito limitam-se a identificar o dogma jurídico no âmbito do conteúdo essencial dos direitos fundamentais, a estabelecer críticas ao dogma jurídico referido e a determinar uma abordagem ao conteúdo essencial dos direitos fundamentais. A metodologia de pesquisa utilizada no manuscrito é de natureza qualitativa porque o problema de investigação proposto envolvia uma análise descritiva da natureza jurídica do conteúdo essencial dos direitos fundamentais. Isto foi feito com um método de pesquisa descritivo-documental, uma vez que o artigo se baseava na doutrina existente sobre o assunto em questão.
\end{abstract}

Palavras-chave: conteúdo essencial, direitos fundamentais, dignidade humana.

O autor: doutora em Direito. Professora na Universidade Católica da Colômbia. E-mail: rcblanco@ ucatolica.edu.co

Recebido: 23 de julho de 2020; avaliado: 20 de setembro de 2020; aceito: 8 de outubro de 2020. 


\section{Introducción}

El ser humano siempre ha pretendido el reconocimiento de derechos fundamentales, en aras de que el individuo gestione un desarrollo integral pleno ${ }^{1}$. Por ello, los referenciados derechos, cuando han sido reconocidos por el Estado, ya sea de manera legislativa o jurisprudencial, suponen la necesidad de protección por parte del ordenamiento jurídico. Lo dispuesto en líneas anteriores es una de las formas de materializar el Estado democrático²; afirmación que está en perfecta concordancia con las reflexiones académicas de la noción de democracia interna ${ }^{3}$ y externa ${ }^{4}$.

Como uno de los instrumentos de protección a los derechos fundamentales, la doctrina alemana y, luego, la española desarrollaron el concepto de contenido esencial de los derechos fundamentales. Es así como en las constituciones alemana y española, y en la jurisprudencia constitucional colombiana, han considerado a la referenciada institución: "como aquel ámbito necesario e irreductible de conducta que el derecho protege, con independencia de las modalidades que asuma éste o de las formas en que se manifieste" , motivo por el cual se ha convertido en un límite infranqueable a la actuación de las autoridades del Estado, en especial al legislativo. Lo anterior, sin que se evidencie a la fecha una explicación unívoca de lo que significa la noción de contenido esencial de los derechos fundamentales. Por ello, por medio de estas páginas, se pretende una aproximación a dicha noción, en aras de ubicar un límite más al papel del legislador cuando regula derechos fundamentales.

1 Carolina Blanco Alvarado, "Condiciones de cohesión entre la Comunidad Andina (CAN) y la descentralización territorial colombiana”, Revista Republicana, vol. 23 (junio, 2017): 23-45. http://ojs.urepublicana. edu.co/index.php/revistarepublicana/article/view/406.

2 Estefanía Acosta Páez y Jorge Enrique León Molina, “Una mirada al derecho internacional desde H. L. A. Hart”, Utopía y Praxis Latinoamericana, vol. 23, supl. 2 (agosto, 2018): 50-57. http://oaji.net/articles/2017/6729-1543684551. pdf; Óscar Alexis Agudelo Giraldo y Camilo Humberto Prieto Fetiva, "A vueltas con la legitimidad democrática. El caso de la explotación minera”, Utopía y Praxis Latinoamericana, vol. 23, extra 2 (agosto, 2018): 26-36. https://www.redalyc.org/jatsRepo/279/27957770002/27957770002.pdf.

3 Flor Ávila Hernández y Édgar Córdova Jaimes, "Democracia y Participación ciudadana en los procesos de la Administración Pública”, Opción, vol. 33, n. 82 (febrero, 2017): 134-159. https://www.redalyc.org/ pdf/310/31053180006.pdf; Jesús Caldera Ynfante, "La democracia como derecho fundamental: Ideas sobre un modelo de democracia integral", Opción, vol. 34, n. ${ }^{\circ} 87$ (noviembre, 2018): 584-624. https://www.researchgate. net/publication/337448543_La_democracia_como_derecho_fundamental_Ideas_sobre_un_modelo_ de_democracia_integral. Lucía Picarella, "Democratic deviations and constitutional changes: The case of Turkey", Academic Journal of Interdisciplinary Studies, vol. 7, n. ${ }^{\circ} 2$ (2018): 9-16. https://www.researchgate. net/publication/326546168_Democratic_Deviations_and_Constitutional_Changes_The_Case_of_Turkey

4 Ricardo Arturo Ariza López, "Los feos, los sucios, los malos: criminalización surrealista de los acontecimientos urbanos", Utopia y Praxis Latinoamericana, vol. 23, extra 1 (julio, 2018): 170-178. https://www.redalyc.org/ jatsRepo/279/27957769010/27957769010.pdf.

5 Sentencia T 473 de 1998, Corte Constitucional Colombiana, Magistrado Ponente: Vladimiro Naranjo Mesa. 
El presente artículo se desarrolló por medio de la metodología de investigación cualitativa, en razón a que pretendió contextualizar la doctrina alemana, y en especial la española, las cuales han desarrollado la temática en particular. Lo anterior, desde el método de investigación descriptivo; esto es, determinando lo que los textos doctrinarios han desarrollado al respecto.

La temática del presente manuscrito resulta de interés, atendiendo el contexto de la justicia transicional, el cual ha sido desarrollado de manera disímil por gran parte de la doctrina ${ }^{6}$; sin embargo, la mayoría de los académicos en el tema en particular coinciden en su importancia frente a la contemporaneidad ${ }^{7}$.

Ahora bien, el problema de investigación planteado en este manuscrito supone reiterar que la naturaleza jurídica de la noción de Estado ha sido contextualizada académicamente desde diferentes perspectivas, las cuales ya no se concentran en el escenario interno ${ }^{8}$, sino, también, en el externo ${ }^{9}$.

6 Carlos Andrés Bernal Castro, "Mutaciones de la criminalidad colombiana en la era del posconflicto", Utopía y Praxis Latinoamericana, vol. 23, extra 1 (julio, 2018): 80-95. https://www.redalyc.org/jatsRepo/279/27957769005/27957769005.pdf; Jaime Cubides, Alexandra Sierra, "Reflexiones en torno a la Justicia Transicional en Colombia: Fuerzas Armadas, Víctimas y posacuerdo", Utopía y Praxis Latinoamericana, vol. 23, extra 2 (2018): 11-24. https://www.produccioncientificaluz.org/index.php/utopia/article/ view/33106/34708; Jaime Cubides Cárdenas, "La implementación del Acuerdo de Paz y la Seguridad en Colombia en el posconflicto", Utopía y Praxis Latinoamericana, vol. 23, extra 2 (2018): 178-193. https:// www.researchgate.net/publication/329424178_La_implementacion_del_Acuerdo_de_Paz_y_la_Seguridad_en_Colombia_en_el_posconflicto; César Castillo Dussan y Manuel Bautista Avellaneda, "Acceso a la justicia alternativa: Un reto complejo", Utopía y Praxis Latinoamericana, vol. 23, extra 2 (agosto, 2018): 163-176. https://produccioncientificaluz.org/index.php/utopia/article/view/33159/34779

7 Pablo Elías González Mongui, "Selectividad penal en la legislación para la Paz de Colombia", Utopía y Praxis Latinoamericana, vol. 23, extra 1 (2019): 131-144. https://produccioncientificaluz.org/index.php/opcion/ article/view/32323/0; Pablo Guadarrama González, "La cultura como condición de paz y la paz como condición de cultura en el pensamiento Latinoamericano", Utopía y Praxis Latinoamericana, vol. 24, extra 1 (2019): 43-66. https://www.redalyc.org/jatsRepo/279/27960978005/html/index.html; Bernardo PérezSalazar, "Construcción de paz en el orden del derecho transnacional penal: El caso colombiano", Utopía y Praxis Latinoamericana, vol. 23, extra 1, (2018): 65-78. https://www.redalyc.org/jatsRepo/279/27957769004/ movil/index.html

8 Gerardo Ruiz Rico y Germán Silva García, "Tendencias y problemas actuales del sistema parlamentario en España”, Utopía y Praxis Latinoamericana, vol. 23, extra 2 (2018): 195-209. https://www.redalyc.org/jatsRepo/279/27957770014/html/index.html; Germán Burgos Silva, "El Estado moderno en cuanto 'abstracción armada'. Algunas reflexiones", Revista Republicana, vol. 24 (agosto, 2018): 105-126. http://ojs. urepublicana. edu.co/index.php/revistarepublicana/article/view/451; Carmen Scocozza, "La Primera Guerra Mundial. Un conflicto que llega desde el Este", Anuario Colombiano de Historia Social y de la Cultura, vol. 42, n. ${ }^{\circ} 2$ (2015): 161-176.

9 Pablo Guadarrama González, "Humanismo práctico y el poder de las instituciones en la gestación del pensamiento político latinoamericano", Utopía y Praxis Latinoamericana, vol. 23, n. ${ }^{\circ} 81-1$ (2018): 13-29. https://www.redalyc.org/jatsRepo/279/27957763003/27957763003.pdf 


\section{El contenido esencial de los derechos fundamentales en la dogmática contemporánea}

En la actualidad, no existe un concepto unívoco de entendimiento de lo que se supone es el contenido esencial de los derechos fundamentales. A pesar de ello, la dogmática jurídica ha desarrollado dos teorías que han pretendido explicar el contenido esencial de los derechos fundamentales como límite de la actividad de regulación por parte del legislador. Al respecto, es importante resaltar lo siguiente: "las doctrinas para determinar el contenido esencial de los derechos fundamentales son muy importantes porque explican cuál debe ser el contenido de un derecho"10. Como lo señala el profesor Otto, el contenido esencial de los derechos fundamentales es un límite a la facultad de regulación de estos por parte del legislativo ${ }^{11}$. En este sentido, resulta procedente afirmar que el legislador puede restringir los derechos fundamentales, siempre y cuando respete su contenido esencial ${ }^{12}$. Al respecto, la doctrina alemana y, luego, la doctrina española han acogido, de manera principal, las teorías relativa y absoluta, las cuales merecen ser analizadas brevemente.

La teoría relativa parte de la afirmación de que toda restricción a los derechos fundamentales exige una justificación, la cual puede encontrar apoyo explícito en la norma constitucional, o bien puede derivarse implícitamente de esta, en cuanto responde a la necesidad de proteger o preservar otros derechos constitucionales o bienes constitucionalmente protegidos ${ }^{13}$. En concordancia con lo dispuesto en líneas anteriores, para la referenciada teoría, y de conformidad con Alexy ${ }^{14}$, el contenido esencial de los derechos fundamentales es aquello que queda después de aplicar el test de ponderación.

Lo anterior permite afirmar que, para la teoría en mención, no existe algún elemento permanente identificable como contenido esencial del derecho (Blanco, 2015) $)^{15}$. Para el efecto, y de conformidad con Gavara: "las teorías relativas consideran, y es

10 Rogelio López Sánchez, "Indeterminación y contenido esencial de los derechos humanos en la Constitución Mexicana", Revista Cuestiones Constitucionales, (2017): 158. http://www.redalyc.org/articulo.oa?id=88553311007

11 Luis Otto De Ignacio, Derechos Fundamentales y Constitución (Madrid: Editorial Civitas, 1988).

12 Antonio Martínez Pujalte, La garantía del contenido esencial de los derechos fundamentales. Cuadernos y debates (Madrid: Editorial Centro de Estudios Constitucionales de Madrid, 1997).

13 Edgar Guarín Ramírez, "Persona y realización efectiva de derechos", Revista IUSTA, vol. 38, n. ${ }^{\circ} 1$ (2013): 133-154.

14 Robert Alexy, Teoría de los derechos fundamentales (Madrid: Editorial Centro de Estudios Constitucionales de Madrid, 1993).

15 Carolina Blanco Alvarado, "La influencia positiva de la CAN en la descentralización territorial colombiana". Revista Opinión Jurídica, vol. 14 n. ${ }^{\circ}$ 27, (2015): 89-98. 
su diferencia sustancial con las teorías absolutas, que el contenido esencial no es una medida preestablecida"16.

En consecuencia, y desde el escenario de la teoría relativa, el contenido esencial de los derechos fundamentales evidencia relevancia en el marco del control de constitucionalidad, en el que se evaluará si el legislativo desconoció o no dicho contenido. Desde la citada perspectiva, el intérprete debe realizar un juicio acerca de la justificación de tal límite o intromisión en el derecho fundamental. Este juicio se sustenta en el llamado test de razonabilidad, o en lo que en la doctrina alemana denominan principio de proporcionalidad en sentido amplio, conformado por tres elementos: el examen de la adecuación de la medida limitadora al bien que mediante ella se pretende proteger; el examen de la necesidad de la lesión del derecho para el fin pretendido, por no existir una alternativa menos gravosa, y el denominado principio de proporcionalidad en sentido estricto, que trata de valorar si la lesión es proporcionada al fin que con ella se pretende ${ }^{17}$. En resumen, el contenido esencial es respetado cuando la limitación se encuentra justificada y no lo es en caso contrario; o dicho con más propiedad: el límite es constitucionalmente correcto cuando se justifica razonablemente en la necesidad de preservar otros bienes constitucionales, y no lo es cuando esa justificación no se da.

En conclusión, bajo la teoría relativa, el contenido esencial de un derecho se vería afectado cuando este experimenta restricción superior a la necesaria para lograr el fin que motiva la limitación. No habría pues, un contenido esencial inamovible, sino que estaría dotado de unas dimensiones variables, dependientes en suma de la peculiar relación medio-fin, resultante de cada correcta limitación que sufriera el derecho. Bajo este prisma, el contenido esencial podría definirse como aquella parte del derecho que comienza cuando el límite deja de ser proporcionado ${ }^{18}$.

Ahora bien, desde el escenario de la teoría absoluta existe una determinada esfera permanente del derecho fundamental que constituye su contenido esencial. La

16 Juan Gavara de Cara, Derechos fundamentales y desarrollo legislativo, la garantía del contenido esencial de los derechos fundamentales en la ley fundamental de Bonn (Madrid: Universitat Autònoma de Barcelona, 1994), 272.

17 Enrique García, La Interpretación de la Constitución (Madrid: Editorial Centro de Estudios Constitucionales de Madrid, 1984) s. p.; Alfonso Daza González, "Legalidad y prescripción frente a la investigación de crímenes de lesa humanidad en Colombia", Revista IUSTA, vol. 38, n. ${ }^{\circ}$ (2013): 205-223. https://www.redalyc.org/ pdf/5603/560358697008.pdf.

18 Jorge Palomares García, "El carácter vinculante de la jurisprudencia constitucional en el derecho alemán", Via Inveniendi Et Iudicandi, vol. 10, n. ${ }^{\circ} 2$ (2016): 29-56. https://revistas.usantotomas.edu.co/index.php/viei/ article/view/2551 
tesis absoluta distingue, en cada derecho, dos partes: un núcleo, que sería el contenido esencial, y una parte accesoria o no esencial. Por lo tanto, desde esta óptica, el contenido esencial es solo una parte del derecho. La diferencia entre ambos radica precisamente en el concepto de esencialidad: solo aquella parte de los elementos integrantes del contenido que sean absolutamente indispensables para la recognoscibilidad jurídica del derecho en cuanto tal puede considerarse constitutiva del contenido esencial. Schneider, por su parte, aporta un criterio en apariencia preciso para identificar esa parte nuclear: "El contenido esencial sería el ámbito mínimo de libre autodeterminación del sujeto, garantizado por cada derecho fundamental, en que se encuentra completamente excluida la actuación estatal"19.

En definitiva, la teoría absoluta, que conecta con la idea de un núcleo resistente al legislador, parte de la consideración de que en todo derecho fundamental existe un componente sustancial que excluye por completo cualquier injerencia de los poderes públicos. Y en este sentido, dicho componente sustancial o núcleo esencial debe ser objeto de precisión, ya que el legislador lo debe conocer para cuando este regule las normas que prevén los derechos fundamentales ${ }^{20}$. Lo más próximo a unas reglas generales para la identificación del contenido esencial de los derechos fundamentales pueden hallarse en la literatura; se pueden citar algunos aportes, como el de Herbert Kruger, en la obra de Martínez, en la cual "se ha de entender violado el contenido esencial cuando ya no puede lograrse el fin por cuyo motivo se confiere el derecho", o el de Ekkehart Stern: "se afecta el contenido esencial, cuando el límite llega tan lejos, que el particular no puede perseguir en absoluto el interés protegido por el derecho"21.

Es importante resaltar que el criterio de la teoría absoluta se suma claramente al grueso de la doctrina, con lo cual se asume generalizadamente que el contenido esencial es el límite de los límites, que cuenta con entidad propia frente al principio de proporcionalidad. En definitiva, desde el escenario de la teoría absoluta, nos encontramos con una descripción espacial del contenido de los derechos fundamentales: existe un espacio interior, en el que la injerencia exterior se encuentra vedada, y un anillo exterior, en el que esa intervención es posible. En este sentido, concebir el contenido esencial como límite de los límites significa ahora que el

\footnotetext{
9 Ludwig Schneider, Der Schutz Des Wesengebalis Von Grundrechten (Berlín: Editorial Berlín, 1990), 23.

20 Alfonso Parejo, "El contenido esencial de los derechos fundamentales en la jurisprudencia constitucional", Revista Española de Derecho Constitucional, n. 3 (1981): 169-189. https://e-archivo.uc3m.es/bitstream/ handle/10016/27596/contenido_parejo_REDC_1981.pdf?sequence=1\&isAllowed=

21 Martínez Pujalte, La Garantía del Contenido Esencial..., 203.
} 
legislador puede establecer restricciones del derecho fundamental solo en su parte accesoria, pero no en su núcleo esencial. Se distingue pues, en cada derecho, una zona que es limitable por el legislador y otra que no es limitable. Así, la cláusula del contenido esencial se interpreta como un límite insuperable que se acredita en sí misma como legítima o suficientemente justificada.

Lo dispuesto anteriormente es corroborado por el profesor Prieto, quien define el contenido esencial como aquella parte del contenido de un derecho, o sea, no es todo el contenido, sino solo una parte, aquella que resulta imprescindible para que el derecho fundamental no deje de existir o no se transforme en algo distinto ${ }^{22}$.

Es necesario resaltar la importancia de los derechos constitucionales frente al ordenamiento jurídico; para ello, la doctrina reiteradamente ha considerado su papel de relevancia ${ }^{23}$. Lo dispuesto anteriormente está en perfecta correspondencia con lo manifestado por gran parte de la doctrina colombiana ${ }^{24}$.

En concordancia con esto, y a pesar de no ser el fundamento principal del presente manuscrito, resulta de interés resaltar el contexto de los derechos fundamentales desde el escenario del derecho constitucional, para lo cual la doctrina ha establecido diferencias sobre el particular ${ }^{25}$. Lo dispuesto anteriormente está en contexto con

22 Luis Prieto Sanchis, Estudios sobre derechos fundamentales (Madrid: Editorial Debate, 1990). https://dialnet. unirioja.es/servlet/autor?codigo $=26632$

23 Natalia Chacón Triana, Carolina Rodríguez Bejarano y Jaime Cubides Cárdenas, "Protección de los derechos fundamentales y terrorismo: dilemas en el uso de la fuerza", Revista Espacios, vol. 39, n. ${ }^{\circ} 16$ (enero 2018): 28-36. https://www.revistaespacios.com/a18v39n16/a18v39n16p28.pdf; Jairo Vladimir Llano Franco, "Globalización del Derecho Constitucional y Constitucionalismo Crítico en América Latina", Utopía y Praxis Latinoamericana, vol. 23, extra 2 (2018): 59-73. https://produccioncientificaluz.org/index.php/utopia/article/ view/33110; Ostau De Lafont De Leon, Francisco Rafael y Leidy Angela Niño Chavarro, "La filosofía del mundo del trabajo en el siglo XXI", Revista Republicana, vol. 22 (2017): 21-46. http://ojs.urepublicana.edu. co/index.php/revistarepublicana/article/view/373

24 Francisco Rafael Ostau De Lafont De Leon y Leidy Angela Niño Chavarro, "Incidencia del derecho internacional del mundo del trabajo en el marco de los derechos humanos en Colombia", Revista Republicana, vol. 20 (2016): 65-96. http://ojs.urepublicana.edu.co/index.php/revistarepublicana/article/view/289

25 Acosta Páez, Una mirada..., 50-57; José Manuel Barreto, "Epistemologies of the south and human rights: Santos and the quest for global and cognitive justice", Indiana Journal of Global Legal Studies, vol. 21, n. 2 (Summer, 2014): 398-422. https://www.repository.law.indiana.edu/ijgls/vol21/iss2/1/; José Manuel Barreto, "Decolonial thinking and the quest for decolonising human rights", Asian Journal of Social Science, vol. 46, n. ${ }^{\circ} 4-5$, (Septiembre, 2018): 484-502. https://doi.org/10.1163/15685314-04604006; Fernanda Navas Camargo, Jaime Cubides Cárdenas, Jesús Enrique Caldera Ynfante "Human Rights Encouragement Through Peaceful Resistance Initiatives in Rural Bogotá", Opción, vol. 34, Especial n. 18 (2018): 2102-2126. https:// produccioncientificaluz.org/index.php/opcion/article/view/24007; Tania Giovanna Vivas Barrera, "Le droit constitutionnel colombien à géométrie variable", Utopía y Praxis Latinoamericana, vol. 23, Extra 2 (2018): 140-150. https://produccioncientificaluz.org/index.php/utopia/article/view/33148. 
lo manifestado por varios académicos colombianos ${ }^{26}$. Lo expuesto no es más que el reconocimiento del papel jurídico de los derechos fundamentale ${ }^{27}$ y su incidencia frente al fenómeno de la globalización.

\section{Principales críticas a las teorías más relevantes que rodean el contenido esencial de los derechos fundamentales}

Cuando se analiza cada una de las interpretaciones de la noción de contenido esencial, es pertinente anotar — por lo que se refiere a la teoría relativa- que es patente cómo desdibuja por completo el sentido de la garantía de protección al contenido esencial de los derechos fundamentales, al convertirla en una garantía meramente formal y retórica; ello permitió fundamentar la tesis difundida en la doctrina alemana acerca de la naturaleza meramente declarativa de la garantía del contenido esencial. Dicha tesis establece que la cláusula del contenido esencial no añade nada a la mención constitucional del derecho fundamental, pues, aunque tal cláusula no existiera, toda limitación de un derecho reconocido constitucionalmente requeriría una justificación. En este sentido, de conformidad con la teoría relativa, se altera de un modo notable la posición constitucional de los derechos, ya que estimar que todo derecho puede quedar limitado con amparo en otros bienes constitucionalmente protegidos, sin requerir más que la proporcionalidad de la medida limitadora en relación con los objetivos perseguidos con ella, equivale a relativizar por completo el estatuto jurídico de los derechos fundamentales, y sujetarlos a la posibilidad de una permanente restricción que puede incluso llegar a su completo sacrificio.

La teoría absoluta, que aparentemente refuerza la protección de los derechos al afirmar en ellos la existencia de un núcleo intangible, plantea en realidad problemas importantes. Al limitar el ámbito vedado a la acción legislativa tan solo a un núcleo duro, y forzar a la distinción, dentro de la esfera protegida por cada derecho, de una parte especial y otra accesoria o accidental, se abre esta última a la libre disposición del legislador, y se relativiza de nuevo la garantía de los derechos fundamentales. Hesse alerta acerca de este riesgo, al indicar que "la teoría absoluta podría sacrificar

26 Alfonso Martínez, Jaime Cubides y María Moreno, "Análisis comparativo de los mecanismos de protección de derechos humanos en la comisión legislativa dentro del ordenamiento jurídico de México y Colombia", Estudios Constitucionales, vol. 15, n. ${ }^{\circ} 2$ (2017): 229-272. https://scielo.conicyt.cl/scielo.php?script=sci_artt ext\&pid=S0718-52002017000200229

27 Navas Camargo, "Human rights encouragement...". https://produccioncientificaluz.org/index.php/opcion/ article/view/24007 
los derechos fundamentales a la libre disposición del legislador, al que solo se le prohíbe tocar un núcleo esencial absoluto que no resulta fácil de determinar"28.

La teoría absoluta se enfrenta, además, con un ineludible problema teórico: obliga a una división en partes — una esencial y otra accidental — del contenido de los derechos fundamentales, división que será con toda frecuencia completamente artificial y que resulta técnicamente insostenible, pues, como apunta con razón Gavara, induce a la curiosa conclusión de que en el ámbito de los derechos fundamentales, el parámetro para el control de constitucionalidad de las disposiciones legislativas lo constituye tan solo una parte de la norma constitucional en la que se reconoce el derecho y no la totalidad de esta ${ }^{29}$.

Por lo demás, la Constitución no ofrece razón alguna para hablar de supuestos contenidos accidentales de los derechos ${ }^{30}$ pues el texto constitucional reconoce los derechos fundamentales en su integridad como ámbitos de protección que constituyen un límite y una orientación para la actuación de los poderes públicos.

En este orden de ideas, la llamada teoría absoluta puede conducir a una relativización del contenido de los derechos fundamentales, precisamente por centrar la construcción dogmática en la garantía del contenido esencial como algo que es objeto de una protección singularizada. Se corre el peligro, con la teoría absoluta, de introducir una relativización de otra índole a la presentada en la teoría relativa: si lo protegido es tan solo el núcleo duro, en torno a este aparece un anillo integrado por una zona penetrable por el legislador, ¿quiere esto decir que en esta zona cabe establecer cualquier límite? ¿O acaso que en ella el derecho no es resistente $?^{31}$.

\section{Problemática sobre el contenido esencial de los derechos fundamentales}

Hart, considerado como uno de los doctrinantes de mayor relevancia del siglo XX, promovió la tesis de la textura abierta del derecho a partir de una premisa muy sencilla, que se circunscribe a afirmar lo siguiente: la razón está en que la necesidad

José López-Medina, El legislador de los derechos fundamentales (Madrid: Editorial Civitas, 1991) 122.

Gavara de Cara, Derechos..., 271.

30 Carolina Blanco Alvarado, "El ámbito del derecho en la descentralización territorial colombiana y la Comunidad Andina (CAN). Revista Republicana, vol. 26 (2019): 93-108. http://ojs.urepublicana.edu.co/index. php/revistarepublicana/article/view/517.

31 De Ignacio, Derechos Fundamentales.... 
de tal elección nos es impuesta porque somos hombres y no dioses. Es por ello que el juez cuenta con un margen de discrecionalidad judicial ante la existencia de zonas de penumbra ${ }^{32}$.

Desde la citada perspectiva, los tribunales constitucionales han acogido la institución del contenido esencial de los derechos fundamentales como límite al legislativo en su actividad de regulación de derechos fundamentales; sin embargo, a la fecha, no existe claridad respecto a su conceptualización, por ello se considera que el contenido esencial de los derechos fundamentales supone un esfuerzo de conceptualización en aras de garantizar la seguridad jurídica que debe orientar la regulación y ejercicio de los derechos fundamentales. Lo anterior, en el marco del cumplimiento de los principios de planeación y transparencia ${ }^{33}$.

Al respecto, es importante anotar que, si bien parte de la doctrina ha considerado la indeterminación del contenido esencial de los derechos fundamentales, aduciendo que la designación de contenido esencial entraña una enérgica reacción contra el positivismo legalista, frente a la citada perspectiva, es importante no olvidar que el contenido esencial de los derechos fundamentales surgió como reacción a la abstracción ${ }^{34}$, y como consecuencia de ello, a la necesidad de precisar su conceptualización.

En la actualidad, no existe - ni nunca ha existido- un concepto estable o seguro de lo que es la esencia; en este sentido, resultan procedentes los siguientes interrogantes: a qué tipo de esencia se refiere la categoría de contenido esencial, ¿la previa al reconocimiento legislativo? o ¿la que deviene con su incorporación al sistema de derecho?

Hay que reconocer que el empleo del término esencial es desafortunado en el marco normativo de derechos fundamentales, pues de antemano nos vincula a un concepto filosófico tan volátil como lo es precisamente la esencia. Este término, si bien en la época de la filosofía clásica fue exacto, es decir, lo que hace a una cosa ser tal cosa, en la actualidad no lo es ${ }^{35}$. Realmente es difícil definir el concepto de esencia, y

32 Adolphus Hart Lionel, El concepto del derecho (Buenos Aires: Editorial Abeledo Perrot, 1998).

33 German Flórez Acero, Sebastián Salazar y Carlos Acevedo, "De la indiferencia pública a la protección de los autores e intérpretes de las producciones de cine en Colombia, a propósito de la ley Pepe Sánchez de 2017" Vniversitas, vol. 67, n. ${ }^{\circ} 136$ (2018): 57-79. https://revistas.javeriana.edu.co/files-articulos/VJ/136\%20 (2018-I)/82555137004/

34 Parejo, "El contenido esencial de los derechos fundamentales...".

35 Julián Mora Ferrater, Diccionario de filosofía de bolsillo (Madrid: Editorial Alianza, 1993). 
más si se tiene en cuenta que a veces se intenta relacionar con otros términos que ostentan su propio y diferente significado, como sucede, por ejemplo, en relación con los términos sustancia y naturaleza ${ }^{36}$.

Atendiendo a la referenciada equivocación, también se ha intentado relacionar los términos esencia y naturaleza jurídica, y, en este sentido, la cuestión que se nos plantea es precisar si la naturaleza jurídica de un derecho fundamental es predicable a la esencia de este (con la finalidad de acercarnos a un concepto más o menos jurídico del término). Al respecto, parte de la doctrina considera que no. De esa manera, la profesora Lorenzo ha considerado que la naturaleza jurídica de un derecho o de una institución es una categoría de la dogmática jurídica. Es decir, es un producto del constructivismo jurídico ${ }^{37}$, por ello no resulta posible asimilar las nociones de esencia y naturaleza jurídica, ya que el contenido esencial de los derechos fundamentales debe ser anterior al referenciado constructivismo jurídico ${ }^{38}$.

En concordancia con lo dispuesto en líneas anteriores, es clara la obligación de que el legislador, cuando proceda con la regulación de los derechos fundamentales, respete su contenido esencial. Sin embargo, en el marco legal no existe ningún mecanismo o metodología para la determinación de dicho contenido, lo que convierte a la garantía del contenido esencial de los derechos fundamentales en un problema interpretativo. Esta situación, de ausencia de determinación del contenido esencial de los derechos fundamentales, implica que los tribunales constitucionales deban gestionar una opción entre dos posibilidades: la primera, consistente en proceder a establecer una metodología para la determinación, en general y en abstracto, del contenido esencial de los derechos fundamentales, es decir, establecer un método útil para determinar el contenido esencial de cualquier derecho fundamental; la segunda, supone renunciar a la anterior posibilidad y proceder, en consecuencia, a determinar el contenido esencial de cada derecho fundamental en concreto y en función de los casos que se plantean ante el tribunal constitucional.

También, dentro de la problemática de la noción del contenido esencial, se encuentra la naturaleza de la defensa de dicho contenido; es decir, si se trata de un tema

36 Magdalena Rodríguez Armas, Análisis del contenido esencial de los derechos fundamentales (Madrid: Editorial Comares, 1996) https://www.marcialpons.es/libros/analisis-del-contenido-esencial-de-los-derechosfundamentales-enunciados-en-el-art-531-de-la-constitucion-espanola/9788481513356/

37 Ibíd.

38 Carolina Blanco Alvarado, "Aproximación a la noción de soberanía estatal en el marco del proceso andino de integración”. Revista Republicana, vol. 15 (2013):34-56 http://revista.urepublicana.edu.co/wp-content/ uploads/2014/04/Aproximacion Nocion.pdf 
extranormativo o si, por el contrario, se trata de un término estrictamente jurídico. Esta última postura es la que adopta Luciano Parejo cuando considera que el contenido esencial de los derechos fundamentales es un concepto jurídico capaz de ser depurado y perfilado técnicamente por medio del control de constitucionalidad que gestiona el tribunal constitucional ${ }^{39}$. En atención a lo dispuesto por el profesor Parejo, es importante resaltar que si tomamos en cuenta, como ya lo hemos apuntado, que esa garantía del contenido esencial surgió para contrarrestar el exceso de formalismo jurídico que desligaba el derecho de los valores y objetivos que le daban razón de ser, volveríamos a caer en ese error si consideramos a ese término únicamente como jurídico. En relación con la opinión de Luciano Parejo, no se puede considerar al contenido esencial como un puro y simple concepto jurídico, ya que el sistema de derecho es por sí mismo incapaz de llenar o construir en forma completa ese concepto; además, la creación mínima de ese vocablo quiere dar la impresión de remitir a criterios extranormativos para su correcta integración.

El contenido esencial de los derechos fundamentales es, en sí mismo, un concepto indeterminado, pero vinculado con criterios valorativos de contenido material que se sustentan en los propios derechos fundamentales, y de ahí su diferencia con el resto de los simples conceptos jurídicos indeterminados. Es por lo anterior que resulta procedente hacer referencia al profesor Prieto Sanchis, quien ha afirmado que el contenido esencial del derecho es un concepto jurídico indeterminado, que pretende referir en términos jurídicos la relevancia de los derechos fundamentales y su protección, ya que, en sí mismos, los derechos fundamentales carecen de un contenido esencial en cuanto a la categoría de derecho fundamental. Para el efecto, el profesor Prieto manifestó:

Definir a priori el contenido esencial de los derechos fundamentales no es una tarea sencilla, pues se trata de un concepto jurídico indeterminado y, además, cada derecho encierra su propio medio de esencialidad, es decir[,] no existe un contenido esencial de la categoría derecho fundamental o al menos no resulta jurídicamente protegido. ${ }^{40}$

En contravía con lo dispuesto por el profesor Prieto, el profesor Lucas Verdu ha considerado que el contenido esencial, como concepto, es algo más fijo y concreto que un simple concepto jurídico indeterminado, que puede ser utilizado para su concreción con elementos del tipo filosóficos, morales, políticos o sociales, en aras de

39 Parejo, "El contenido esencial de los derechos...".

40 Prieto Sanchis, Estudios sobre derechos fundamentales, 139. 
apoyar el proceso de materialización del Estado de derecho ${ }^{41}$. En concordancia con lo dispuesto en líneas anteriores, y como una problemática adicional a la concreción del contenido esencial de los derechos fundamentales, es necesario tener en cuenta que el hecho de que tratemos de concretar los términos propios del contenido esencial puede entrañar un riesgo considerable $e^{42}$ : que el contenido esencial se convierta en un concepto modificable, variable con el paso del tiempo y, en especial, por las necesidades concretas de cada momento, lo cual podría comportar la relativización del concepto del contenido esencial ${ }^{43}$.

\section{Una posible aproximación a la determinación del contenido esencial de los derechos fundamentales}

En aras de determinar el contenido esencial de los derechos fundamentales, es preciso no olvidar — de conformidad con Motta— que: "los Derechos Fundamentales son de la persona y revelan principalmente su trascendencia moral, por ello no es posible identificarlos como una construcción teórica que tiene una aplicación práctica en la vida social" ${ }^{4}$.

Antes de acercarse a una posible definición del concepto del contenido esencial de los derechos fundamentales, es preciso preguntarse si resulta determinable el contenido esencial de dichos derechos y, de ser factible, cómo se puede llegar a conocer su contenido esencial. Al respecto, es pertinente anotar que, cuando hablamos de determinar el contenido esencial de los derechos fundamentales, no estamos pretendiendo crear dicho contenido, pues determinar y crear son dos cuestiones diferentes. Se considera que el contenido esencial de los derechos fundamentales es anterior a su regulación constitucional, al igual que algunos principios y valores constitucionales. En otras palabras, el contenido esencial tiene un carácter de preexistencia a la norma constitucional ${ }^{45}$.

Pablo Lucas Verdu, Estimativa y política constitucionales (Madrid: Editorial Civitas, 2008).

42 Nohora Pardo Posada, "Un recorrido por los derechos colectivos en la jurisprudencia Argentina", Revista Via Inveniendi et Iudicandi, vol. 9, n. ${ }^{\circ} 1$ (2014): 32-49.

43 Sonia Cortez Zambrano, "Derechos humanos en las políticas de paz y posconflicto en Colombia" Via Inveniendi et Iudicandi, vol. 11, n. ${ }^{\circ}$ (2016): 24-35. https://revistas.usantotomas.edu.co/index.php/viei/article/ view/2926; Sonia Cortez Zambrano, "La globalización económica y los derechos humanos", Revista Via Inveniendi et Iudicandi, vol. 11, n. 1 (2013): 24-35. https://revistas.usantotomas.edu.co/index.php/viei/ article/view/1163

44 Álvaro Andrés Motta Navas, "Hacia la determinación del contenido esencial de los derechos fundamentales", Revista Universitas, n. ${ }^{\circ} 110$ (2005): 531.

45 José Ramón Cossio Díaz, Estado social y derechos de prestación (Madrid: Editorial Centro de Estudios Constitucionales, 1989). 
Consideramos que el contenido esencial de los derechos fundamentales es la propia dignidad humana, valor absoluto en todas las coordenadas de tiempo o espacio que se quiera contemplar. La dignidad de la persona humana no conoce tendencias jurídicas, ideológicas, políticas o económicas ${ }^{46}$. Al respecto, es pertinente anotar que la noción de dignidad referida no implica una categoría dinámica, como algo que debe conquistarse, sino que debe entenderse de modo estático, como algo ya dado y que no puede perderse ${ }^{47}$. La dignidad humana ha de ser comprendida como el valor constitucional que materializa otros valores constitucionales ${ }^{48} ; y$, atendiendo lo dispuesto por Maritain, es un concepto absoluto que permite la realización integral del ser humano ${ }^{49}$. En este orden de ideas, el contenido esencial de los derechos fundamentales es un fragmento, un núcleo interno o reducto del derecho ${ }^{50}$; es lo que debe permanecer vivo a pesar del tiempo, lo que persiste abierto al cambio, reconocible siempre. En este orden de ideas, los derechos fundamentales aparecen fragmentados por un núcleo indisponible y resistente a todo cambio ${ }^{51}$, el cual se configura como el contenido esencial de los derechos fundamentales, y que resulta equivalente a la noción de dignidad humana ${ }^{52}$.

Lo dispuesto en las líneas anteriores está reiterado por gran parte de la doctrina colombiana $^{53}$. La citada fuente del derecho ha intentado contextualizar, desde la modernidad, la disciplina del derecho penal ${ }^{54}$, lo cual es corroborado por gran parte de académicos colombianos ${ }^{55}$.

46 Miguel Carlos Ruiz, El significado jurídico del principio de la dignidad de la persona en el ordenamiento español (Madrid: Editorial Edeval, 1995).

47 Rodríguez Armas, Análisis del contenido....

48 Pablo Lucas Verdu, Curso de Derecho Político (Madrid: Editorial Tecnos, 1984).

49 Jacques Maritan, El hombre y el Estado (Madrid: Editorial Civitas, 1983).

50 Antonio Enrique Pérez-Luño, Derechos Humanos, Estado de Derecho y Constitución. Madrid, España: Editorial Tecnos, 1984.

51 Alfonso Parejo, "El contenido esencial de los derechos fundamentales en la jurisprudencia constitucional", Revista Española de Derecho Constitucional, n. ${ }^{\circ}$ (1981): 169-189. https://e-archivo.uc3m.es/bitstream/ handle/10016/27596/contenido_parejo_REDC_1981. pdf?sequence=1\&isAllowed=y

52 Sandra Gamboa Rubiano, "A propósito de una verdad contrahegemónica: aprendizajes desde la decisión de la Corte Penal Internacional sobre el ataque contra la flotilla de la libertad", Via Inveniendi et Iudicandi, vol. 11, n. ${ }^{\circ}$ ( (2016): 11-35. https://revistas.usantotomas.edu.co/index.php/viei/article/view/2925

53 Manuel Fernando Moya Vargas, "Sentido de justicia y proceso penal", Utopía y Praxis Latinoamericana, vol. 23, Extra 1 (2018): 50-63. https://www.redalyc.org/jatsRepo/279/27957769003/27957769003.pdf

54 Jorge Restrepo Fontalvo, "Feminizar a los hombres para prevenir la criminalidad", Utopía y Praxis Latinoamericana, vol. 23, extra 1 (2018): 112-129. https://go.gale.com/ps/anonymous?id=GALE\%7CA58389519 $8 \&$ sid=googleScholar\&v=2.1\&it=r\&linkaccess=abs\&issn=13165216\&p=IFME\&sw=w

55 Henry Torres Vásquez, Misael Tirado Acero y Sergio Trujillo Florián, "El funcionalismo radical penal a partir de la bioética", Revista Republicana, vol. 25 (2018): 179-198; Rafael Velandia Montes, Misael Tirado Acero y Alejandro Gómez Jaramillo, "Cadena perpetua y predicción del comportamiento. Un análisis sobre la delincuencia en contra de menores de edad y la política penal en Colombia", Revista Republicana, vol. 25 (2018): 241-263. 


\section{Conclusiones}

El contenido esencial de los derechos fundamentales es un límite al poder legislativo en su función de regulador de derechos fundamentales. Es pertinente anotar que, cuando hablamos de determinar el contenido esencial de los derechos fundamentales, no estamos pretendiendo crear dicho contenido, pues determinar y crear son dos casos diferentes. El contenido esencial a los derechos fundamentales es anterior a su regulación constitucional.

El hecho de que tratemos de concretar el concepto del contenido esencial puede entrañar un riesgo considerable: el riesgo que conllevaría la determinación no es otro que hacer del contenido esencial un concepto modificable, variable con el paso del tiempo y las circunstancias que se impongan. Ello podría comportar la relativización del concepto del contenido esencial, con lo cual, y en aras de evitar lo dispuesto anteriormente, es procedente afirmar que la esencia del contenido es la propia dignidad humana, valor absoluto en todas las coordenadas de tiempo o espacio que se quieran contemplar.

El contenido esencial sostiene la existencia de un ámbito nuclear de los derechos fundamentales, sin el cual estos se desnaturalizan y dejan de responder a su denominación formal, y, por tanto, la posibilidad de la fijación de ese ámbito equivalente, constitucionalmente hablando, a su contenido esencial.

Cuando se analiza la noción del contenido esencial de los derechos fundamentales, atendiendo a las teorías absoluta y relativa, es la teoría absoluta, por lo pronto, la que se adapta mejor a la expresión lingüística "contenido esencial", equivalente en el lenguaje ordinario a contenido básico o elemental, y que alude así a ese corazón o núcleo al que se refiere la teoría absoluta.

El contenido esencial de los derechos fundamentales es un concepto de valor absoluto y no relativo; esto quiere decir que cualquiera que fueren las circunstancias invocadas para la limitación del derecho, este ha de conservar siempre sus rasgos esenciales, y configurarse como una esfera de intangibilidad que nunca, en ningún caso, puede sobrepasarse. 


\section{Referencias bibliográficas}

Acosta Páez, Estefanía y Jorge Enrique León Molina. "Una mirada al derecho internacional desde H. L. A. Hart". Utopía y Praxis Latinoamericana, vol. 23, supl. 2 (2018): 50-57. https://www.redalyc.org/jatsRepo/279/27957770004/27957770004.pdf

Agudelo Giraldo, Óscar Alexis y Camilo Humberto Prieto Fetiva. "A vueltas con la legitimidad democrática. El caso de la explotación minera". Utopía y Praxis Latinoamericana, vol. 23, extra 2 (2018): 26-36. https://www.redalyc.org/jatsRepo/279/27957770002/27957770002.pdf

Alexy, Robert. Teoría de los derechos fundamentales. Madrid: Editorial Centro de Estudios Constitucionales, 1993.

Ariza López, Ricardo Arturo. "Los feos, los sucios, los malos: criminalización surrealista de los acontecimientos urbanos”. Utopía y Praxis Latinoamericana, vol. 23, extra 1 (2018): 170-178. https://www.redalyc.org/jatsRepo/279/27957769010/27957769010.pdf

Ávila Hernández, Flor y Édgar Córdova Jaimes. "Democracia y participación ciudadana en los procesos de la Administración Pública”. Opción, vol. 33 n. 82 (2017): 134-159 https://www.redalyc.org/pdf/310/31053180006.pdf

Barreto, José Manuel. "Decolonial thinking and the quest for decolonising human rights". Asian Journal of Social Science, vol. 46 n. ${ }^{\circ}$ 4-5 (2018): 484-502. https://doi. org/10.1163/15685314-04604006

Barreto, Jose Manuel. "Epistemologies of the south and human rights: Santos and the quest for global and cognitive justice". Indiana Journal of global legal studies, vol. 21 n. 2 (2014): 398-422. https://www.repository.law.indiana.edu/ijgls/vol21/iss2/1/

Bernal Castro, Carlos Andrés. "Mutaciones de la criminalidad colombiana en la era del Posconflicto”. Utopía y Praxis Latinoamericana, vol. 23, extra 1 (2018): 80-95. https:// www.redalyc.org/jatsRepo/279/27957769005/27957769005.pdf

Blanco Alvarado, Carolina. "El ámbito del derecho en la descentralización territorial colombiana y la Comunidad Andina (CAN). Revista Republicana, vol. 26 (2019): 93-108. http://ojs.urepublicana.edu.co/index.php/revistarepublicana/article/view/517. Blanco Alvarado, Carolina. "Algunas propuestas frente a la crisis de legitimidad de la Comunidad Andina”. Revista Análisis Político, vol. 26, n. 78 (2013): 23-45.

Blanco Alvarado, Carolina. "Aproximación a la noción de soberanía estatal en el marco del proceso andino de integración”. Revista Republicana, vol. 15 (2013): 34-56 http://revista. urepublicana.edu.co/wp-content/uploads/2014/04/Aproximacion Nocion.pdf

Blanco Alvarado, Carolina. "Condiciones de cohesión entre la Comunidad Andina (CAN) y la descentralización territorial colombiana”. Revista Republicana, vol. 23 (2017): 23-45. http://ojs.urepublicana.edu.co/index.php/revistarepublicana/article/view/406. 
Blanco Alvarado, Carolina. "La influencia positiva de la CAN en la descentralización territorial colombiana”. Revista Opinión Jurídica, vol. 14 n. ${ }^{\circ}$ 27, (2015): 89-98.

Burgos Silva, Germán. "El Estado moderno en cuanto 'abstracción armada'. Algunas reflexiones". Revista Republicana, vol. 24 (2018): 105-126.

Caldera Ynfante, Jesús. "La democracia como derecho fundamental: Ideas sobre un modelo de democracia integral". Opción, vol. 34 n. ${ }^{\circ}$ 87, (2018): 584-624. https://www.researchgate.net/publication/337448543_La_democracia_como_derecho_fundamental_Ideas_sobre_un_modelo_de_democracia_integral

Castillo Dussan, César y Manuel Bautista Avellaneda. "Acceso a la justicia alternativa: Un Reto Complejo". Utopía y Praxis Latinoamericana, vol. 23, extra 2 (2018): 163-176. https://produccioncientificaluz.org/index.php/utopia/article/view/33159/34779

Chacón Triana, Natalia, Carolina Rodríguez Bejarano y Jaime Cubides Cárdenas. "Protección de los derechos fundamentales y terrorismo: dilemas en el uso de la fuerza". Revista Espacios, vol. 39 n. ${ }^{\circ} 16$ (enero 2018): 28-36. https://www.revistaespacios.com/a18v39n16/a18v39n16p28.pdf

Cortez Zambrano, Sonia. "Derechos humanos en las políticas de paz y posconflicto en Colombia". Via Inveniendi et Iudicandi, vol. 11, n. ${ }^{\circ}$ (2016): 24-35. https://revistas. usantotomas.edu.co/index.php/viei/article/view/2926

Cortez Zambrano, Sonia. "La globalización económica y los derechos humanos". Via Inveniendi et Iudicandi, vol. 11, n. ${ }^{\circ} 1$ (2013): 24-35 https://revistas.usantotomas.edu. co/index.php/viei/article/view/1163

Cossio Díaz, José Ramón. Estado social y derechos de prestación. Madrid: Editorial Centro de Estudios Constitucionales, 1989.

Cubides Cárdenas, Jaime y Jesús Ynfante Caldera. "La Implementación del Acuerdo de Paz y la Seguridad en Colombia en el Posconflicto". Opción, vol. 23, extra 2 (2018): 178-193. Cubides Jaime, Alexandra Sierra. "Reflexiones en torno a la Justicia Transicional en Colombia: Fuerzas Armadas, Víctimas y posacuerdo". Utopía y Praxis Latinoamericana, vol. 23, extra 2 (2018): 11-24 https://www.produccioncientificaluz.org/index.php/ utopia/article/view/33106/34708

Daza González, Alfonso. "Legalidad y prescripción frente a la investigación de crímenes de lesa humanidad en Colombia”. Revista IUSTA, vol. 38, n. 1 (2013): 205-223. https:// www.redalyc.org/pdf/5603/560358697008.pdf

De Ignacio, Luis Otto. Derechos fundamentales y constitución. Madrid: Editorial Civitas, 1988.

De Lafont De Leon, Ostau, Francisco Rafael y Leidy Ángela Niño Chavarro. "La filosofía del mundo del trabajo en el siglo XXI". Revista Republicana, vol. 22 (2017): 21-46. http://ojs.urepublicana.edu.co/index.php/revistarepublicana/article/view/373

De Lafont De Leon, Ostau, Francisco Rafael y Leidy Ángela Niño Chavarro. "Incidencia del derecho internacional del mundo del trabajo en el marco de los derechos humanos 
en Colombia”. Revista Republicana, vol. 20 (2016): 65-96. http://ojs.urepublicana. edu.co/index.php/revistarepublicana/article/view/289

Flórez Acero, Germán, Sebastián Salazar y Carlos Acevedo. "De la indiferencia pública a la protección de los autores e intérpretes de las producciones de cine en Colombia, a propósito de la ley Pepe Sánchez de 2017". Vniversitas, vol. 67, n. ${ }^{\circ} 136$ (2018): 57-79. https://revistas.javeriana.edu.co/files-articulos/VJ/136\%20(2018-I)/82555137004

Gamboa Rubiano, Sandra. "A propósito de una verdad contrahegemónica: aprendizajes desde la decisión de la Corte Penal Internacional sobre el ataque contra la flotilla de la libertad". Via Inveniendi et Iudicandi, vol. 11, n. ${ }^{\circ} 1$ (2016): 11-35. https://revistas. usantotomas.edu.co/index.php/viei/article/view/2925

García, Enrique. La interpretación de la constitución Madrid: Editorial Centro de Estudios Constitucionales, 1984.

Gavara de Cara, Juan. Derechos fundamentales y desarrollo legislativo, la garantía del contenido esencial de los derechos fundamentales en la ley fundamental de Bonn. Madrid: Universitat Autònoma de Barcelona, 1994.

González Mongui, Pablo Elías. "Selectividad penal en la legislación para la Paz de Colombia”. Utopía y Praxis Latinoamericana, vol. 23, extra 1 (2019): 131-144. https:// produccioncientificaluz.org/index.php/opcion/article/view/32323/0

Guadarrama González, Pablo. "Humanismo práctico y el poder de las instituciones en la gestación del pensamiento político latinoamericano". Utopía y Praxis Latinoamericana, vol. 23, n. ${ }^{\circ}$ 81-1 (2018): 13-29. https://www.redalyc.org/jatsRepo/279/27957763003/27957763003.pdf

Guadarrama González, Pablo. "La cultura como condición de paz y la paz como condición de cultura en el pensamiento Latinoamericano". Utopía y Praxis Latinoamericana, vol. 24, extra 1 (2019): 43-66. https://www.redalyc.org/jatsRepo/279/27960978005/ html/index.html

Guarín Ramírez, Édgar. "Persona y realización efectiva de derechos". Revista IUSTA, vol. 38, n. ${ }^{\circ} 1$ (2013): 133-154.

Hart Lionel, Adolphus. El concepto del derecho. Buenos Aires: Editorial Abeledo Perrot, 1998. Llano Franco, Jairo Vladimir. "Globalización del derecho constitucional y constitucionalismo crítico en América Latina”. Utopía y Praxis Latinoamericana, vol. 23, Extra 2 (2018): 59-73. https://produccioncientificaluz.org/index.php/utopia/article/view/33110

López Medina, José. El legislador de los derechos fundamentales. Madrid: Editorial Civitas, 1991. López Sánchez, Rogelio. "Indeterminación y contenido esencial de los derechos humanos en la Constitución Mexicana". Revista Cuestiones Constitucionales, (2017): 67-97. http://www.redalyc.org/articulo.oa?id=88553311007

Lucas Verdu, Pablo. Curso de Derecho Político. Madrid: Editorial Tecnos, 1984.

Lucas Verdu, Pablo. Estimativa y Política constitucionales. Madrid: Editorial Civitas, 2008. 
Martínez Pujalte, Antonio. La garantía del contenido esencial de los derechos fundamentales. Cuadernos y Debates. Madrid: Editorial Centro de Estudios Constitucionales, 1997. Martínez, Alfonso, Jaime Cubides y María Moreno. "Análisis comparativo de los mecanismos de protección de derechos humanos en la comisión legislativa dentro del ordenamiento jurídico de México y Colombia”. Estudios Constitucionales, vol. 15, n. 2 (2017): 229-272. Matitan, Jacques. El hombre y el Estado. Madrid: Editorial Civitas, 1983.

Mora Ferrater, Julián. Diccionario de filosofía de bolsillo. Madrid: Editorial Alianza, 1993. Motta Navas, Álvaro Andrés. "Hacia la determinación del contenido esencial de los derechos fundamentales". Revista Universitas, n. ${ }^{\circ} 110$ (2005): 519-542.

Moya Vargas, Manuel Fernando. "Sentido de justicia y proceso penal". Utopía y Praxis Latinoamericana, vol. 23, extra 1 (2018): 50-63.

Navas Camargo, Fernanda, Jaime Cubides Cárdenas y Jesús Enrique Caldera Ynfante. "Human rights encouragement through peaceful resistance initiatives in rural Bogotá". Opción, vol. 34, especial n. ${ }^{\circ} 18$ (2018). https://produccioncientificaluz.org/index. php/opcion/article/view/24007

Palomares García, Jorge. "El carácter vinculante de la jurisprudencia constitucional en el derecho alemán". Via Inveniendi Et Iudicandi, vol. 10, n. 2 (2016): 29-56. https:// revistas.usantotomas.edu.co/index.php/viei/article/view/2551

Pardo Posada, Nohora. "Un recorrido por los Derechos Colectivos en la Jurisprudencia Argentina". Revista Via Inveniendi et Iudicandi, vol. 9, n. ${ }^{\circ} 1$ (2014): 32-49.

Parejo, Alfonso. "El contenido esencial de los derechos fundamentales en la jurisprudencia constitucional", Revista Española de Derecho Constitucional, n. 3 (1981): 169-189. https://e-archivo.uc3m.es/bitstream/handle/10016/27596/contenido_parejo_REDC _1981. pdf? sequence=1 \&isAllowed $=y$

Pérez-Luño, Antonio Enrique. Derechos Humanos, Estado de Derecho y Constitución. Madrid, España: Editorial Tecnos, 1984.

Pérez-Salazar, Bernardo. "Construcción de paz en el orden del derecho transnacional penal: El caso colombiano". Utopía y Praxis Latinoamericana, vol. 23, extra 1 (2018): 65-78. https://www.redalyc.org/jatsRepo/279/27957769004/movil/index.html

Picarella, Lucía. "Democratic deviations and constitutional changes: The case of Turkey". Academic Journal of Interdisciplinary Studies, vol. 7, n. 2 (2018): 9-16. https://www. researchgate.net/publication/326546168_Democratic_Deviations_and_Constitutional_Changes_The_Case_of_Turkey

Prieto Sanchis, Luis. Estudios sobre derechos fundamentales. Madrid: Editorial Debate, 1990. https://dialnet.unirioja.es/servlet/articulo? codigo=5630503

Restrepo Fontalvo, Jorge. "Feminizar a los hombres para prevenir la criminalidad". Utopía y Praxis Latinoamericana, vol. 23, extra 1 (2018): 112-129. https://go.gale.com/ps/ 
anonymous?id=GALE\% 7CA583895198\&sid=googleScholar\&v=2.1\&it=r\&linkacce $\mathrm{ss}=\mathrm{abs} \& \mathrm{issn}=13165216 \& \mathrm{p}=\mathrm{IFME} \& \mathrm{sw}=\mathrm{w}$

Rodríguez Armas, Magdalena. Análisis del contenido esencial de los derechos fundamentales. Madrid: Editorial Comares, 1996. https://www.marcialpons.es/libros/analisis-delcontenido-esencial-de-los-derechos-fundamentales-enunciados-en-el-art-531-de-laconstitucion-espanola/9788481513356/

Ruiz Rico, Gerardo y German Silva García. "Tendencias y problemas actuales del sistema parlamentario en España”. Utopía y Praxis Latinoamericana, vol. 23, extra 2 (2018): 195-209. https://www.redalyc.org/jatsRepo/279/27957770014/html/index.html

Ruiz, Miguel Carlos. El significado jurídico del principio de la dignidad de la persona en el ordenamiento español. Madrid (España): Editorial Edeval, 1995.

Schneider, Ludwig. Der Schutz Des Wesengebalis Von Grundrechten. Berlin: Editorial Berlín, 1990.

Scocozza, Carmen. "La Primera Guerra Mundial: Un conflicto que llega desde el Este". Anuario Colombiano de Historia Social y de la Cultura, vol. 42, n. ${ }^{\circ} 2$ (2015):161-176.

Sentencia T 473 de 1998. Corte Constitucional Colombiana, M. P Naranjo Mesa.

Tirado Acero, Misael, Carlos Alfonso Laverde Rodríguez y Juan Camilo Bedoya Chavarriaga. "Prostitución en Colombia: hacia una aproximación socio jurídica a los derechos de los trabajadores sexuales". Revista Latinoamericana de Derecho Social, vol. 29 (2019): 289-315.

Torres Vásquez, Henry, Misael Tirado Acero y Sergio Trujillo Florián. "El funcionalismo radical penal a partir de la bioética". Revista Republicana, vol. 25 (2018): 179-198.

Velandia Montes, Rafael, Misael Tirado Acero y Alejandro Gómez Jaramillo. "Cadena perpetua y predicción del comportamiento. un análisis sobre la delincuencia en contra de menores de edad y la política penal en Colombia”. Revista Republicana, vol. 25 (2018): 241-263.

Vivas Barrera, Tania Giovanna. "Le droit constitutionnel colombien à géométrie variable". Utopía y Praxis Latinoamericana, vol. 23, extra 2 (2018): 140-150 https://produccioncientificaluz.org/index.php/utopia/article/view/33148 